\title{
Chapter 13 \\ Between Explanans and Explanandum: Biodiversity and the Unity of Theoretical Ecology
}

\section{Philippe Huneman}

\begin{abstract}
Biodiversity is arguably a major topic in ecology. Some of the key questions of the discipline are: why are species distributed the way they are, in a given area, or across areas? Or: why are there so many animals (as G. Evelyn Hutchinson asked in a famous paper)? It appears as what is supposed to be explained, namely an explanandum of ecology. Various families of theories have been proposed, which are nowadays mostly distinguished according to the role they confer to competition and the competitive exclusion principle. Niche theories, where the difference between "fundamental" and "realised" niches (Hutchinson GE, Am Nat 93:145159, 1959) through competitive exclusion explains species distributions, contrast with neutral theories, where an assumption of fitness equivalence, species abundance distributions are explained by stochastic models, inspired by (Hubbell SP, The unified neutral theory of biodiversity and biogeography. Princeton University Press, Princeton, 2001).

Yet, while an important part of community ecology and biogeography understands biodiversity as an explanandum, in other areas of ecology the concept of biodiversity rather plays the role of the explanans. This is manifest in the long lasting stability-diversity debate, where the key question has been: how does diversity beget stability? Thus explanatory reversibility of the biodiversity concept in ecology may prevent biodiversity from being a unifying object for ecology.

In this chapter, I will describe such reversible explanatory status of biodiversity in various ecological fields (biogeography, functional ecology, community ecology). After having considered diversity as an explanandum, and then as an explanans, I will show that the concepts of biodiversity that are used in each of these symmetrical explanatory projects are not identical nor even equivalent. Using an approach to the concept of biodiversity in terms of "conceptual space", I will finally argue that the lack of unity of a biodiversity concept able to function identically as explanans and explanandum underlies the structural disunity of ecology that has been pointed out by some historians and philosophers.
\end{abstract}

P. Huneman $(\bowtie)$

Institut d'Histoire et de Philosophie des Sciences et des Techniques, CNRS/Université Paris I

Panthéon Sorbonne, Paris, France

(C) The Author(s) 2019

E. Casetta et al. (eds.), From Assessing to Conserving Biodiversity,

History, Philosophy and Theory of the Life Sciences 24,

https://doi.org/10.1007/978-3-030-10991-2_13 
Keywords Explanation $\cdot$ Species richness $\cdot$ Functional diversity $\cdot$ Phylogenetic diversity $\cdot$ Modern Synthesis $\cdot$ Neutral theory $\cdot$ Niche $\cdot$ Stability

\subsection{Introduction}

Amongst the questions that theoretical ecologists have been debating for decades one finds: why are species distributed the way they are, in a given area, or across areas? How is biodiversity related to areas? Why are there so many species in tropical regions? In general, why are there so many animals (as Hutchinson asked in a famous paper)? Is the amount of species currently decreasing and at what tempo? Why are so many species getting extinct in some environments now? Those questions have to do with what we have been calling, since Walter G. Rosen coined the word in the 80s (Takacs 1996) and Wilson $(1988,1992)$ popularized it, "biodiversity".

However, there are many ways of measuring biodiversity, tracking its progress or, more realistically, its erosion: different measurement methods defined by different indexes, such as Shannon index, Simpson index, etc. (Gosselin 2014; Noss 1990), as well as various ways of capturing it in relation to the ecological scale, such as beta diversity, gamma diversity, ${ }^{1}$ etc. Moreover, there are several concepts of biodiversity, some attributing species a privileged role and others including also genes, or ecosystems, as is attested in the definition of biodiversity used in international conventions, such as the Convention on Biological Diversity (1992): "'Biological diversity' means the variability among living organisms from all sources including inter alia, terrestrial, marine and other aquatic ecosystems, and the ecological complexes of which they are a part; this includes diversity within species, between species and of ecosystems". And even at the level of species diversity, species richness as the mere amount of species is often considered too rough a biodiversity concept. In order to design robust diversity indices, ecologists or conservation biologists often add species evenness, and then consider the width of diversity, named as disparity - some wanting also to integrate the consideration of abundances within the concept of diversity (Blandin 2014). In addition to mere species counting, however, some dimension of species similarity sometimes ought to be included in the concept of diversity: mitigating species diversity by functional or phylogenetic similarity results in the concepts of phylogenetic diversity or functional diversity, whose use is especially required in ecophylogenetics (Mouquet et al. 2012) for the former and in functional ecology for the latter.

\footnotetext{
${ }^{1}$ Those terms were introduced by Whittaker to capture aspects of the local and regional distributions of diversity. Alpha diversity refers to species diversity on sites or habitats at a local scale as well as to the ratio of local to regional diversity, beta diversity compares the species diversity between ecosystems or across environmental gradients; gamma diversity is the total diversity in a landscape and therefore the compound of the former two.
} 
Thus, while it was tempting in the beginning to consider biodiversity as a key question and a key explanandum of ecology, the diversity of biodiversity prevents us from straightforwardly claiming this. It may be argued, in turn, that this diversity seems to echo a lack of unity that affects ecology itself. It has indeed often been complained in ecology that the field lacks the unity that characterises the sister field of evolutionary biology. In 1989, Hagen already saw ecology as affected by a deep cleavage between a holological perspective and a mereological perspective, the latter using a demographic approach to ecosystems and communities while the former relies on a systemic view of the ecological objects, with or without appealing to evolutionary schemes of thought and natural selection (Hagen 1989). He concluded that this cleavage is essential to the discipline, and in turn allows ecology to explore a wide variety of objects and problems. More recently, Vellend (2016) has explicitly drawn a parallel between evolutionary biology and ecology and argued that ecology never had a unified framework similar to the one that structured evolutionary biology from the 50s onwards, and that allowed this science to flourish by providing researchers with common concepts, methods, key examples, key issues, and references.

Would it make sense to consider that the diversity of biodiversity is involved in the lack of unity of theoretical ecology? Or, more precisely, which disunity would be induced by this diversity, and is it unredeemable?

This will be the main question of the chapter. I will start by considering the issue of the long sought unity of ecology (13.2). Then I will explicate what I call the "explanatory reversibility" of biodiversity in ecology, namely its capacity to be explanandum and explanans in a science, as an essential feature of its theoretical role (13.3). Section 13.4 will consider more precisely the aspects of diversity as an explanandum of various ecological programmes, involving distinct explanatory schemes. Section 13.5 turns to diversity as an explanans, focusing on the relations between various kinds of stability and distinct notions of diversity, and characterizing the differences between such diversity and the way diversity is used in the explanatory programmes formerly described. In Sect. 13.6, I propose an account of the ecological notion of diversity in terms of a "conceptual space", in which various biodiversity concepts used in the varied explanatory strategies I described are specifically constructed. I use it in order to explicate the specific profile of the explanatory reversibility of diversity in ecology, and draw conclusions about the lack of unity in ecology and the epistemic status of the notion of diversity. The major argument developed there relies on the fact that the two explanatory projects concerning diversity target different "regions" of the total conceptual space of biodiversity so described. 


\subsection{The Unity of Ecology}

It is often heard that ecology lacks unity - be it to complain about the missing unity (Vellend 2010), or to claim that it is a richness proper to this scientific discipline (Hagen 1989). Inversely, "unifying principles" or theories have been constantly pursued for ecology (e.g. Margalef 1963; Hubbell 2001; Loreau 2010; Vellend 2016). Before considering the specific theoretical role of a biodiversity concept in ecology, and the possible unifying role it could play as an object or a pervasive concept, I will review the most general divides that seem to prevent such unity. After having listed some subfields, I will attempt at ordering this disunity by indicating the major lines of division (summarized in Fig. 13.1 below).

A quick glance at ecological subdisciplines shows the overall variety of questions and methods that characterizes the field. Behavioural ecology studies the traits ("behaviours") of organisms, hypothesized as adaptations to their (possibly social) environment; community ecology is about communities, i.e. sets of various species in the same region, considered from the viewpoint of the diversity and succession of species occurring within it. Population ecology mostly considers few species and focuses on the dynamics of the abundances of each of them given their major ecological interactions (predation or competition). Biogeography is interested in the distribution of species across higher scale dimensions, namely regions. Functional ecology considers the interactions between various species from the viewpoint of their net effect on the shared environment, especially by addressing networks of trophic relations and ascribing its species a role in the ecosystem (Loreau 2010). Ecosystem ecology as advocated by the Odum brothers (e.g. Odum 1953) develops such approach and uses schemes of thermodynamic thinking in considering ecosystems (i.e. communities plus their abiotic environment) under the perspective of semi-closed systems exchanging matter and energy with their environment (Hagen 1992). On the other hand, Ecological genetics initiated by E.B. Ford (Ford 1964) - a student of Fisher - considers the dynamics of population in various species from the standpoint of the changes of gene frequency within each species. Finally, evolutionary ecology (Roughgarden 1979) borrows tools from ecological genetics and approaches ecological patterns as results of evolutionary processes.

Fig. 13.1 The divides of ecology. Each thick line represents one of the four dimensions. The thin lines stand for the position of three historically important views in ecology: in black, Clements (1916); in red, Allee et al. (1949); in blue Nicholson and Bailey (1935) (Color figure online)

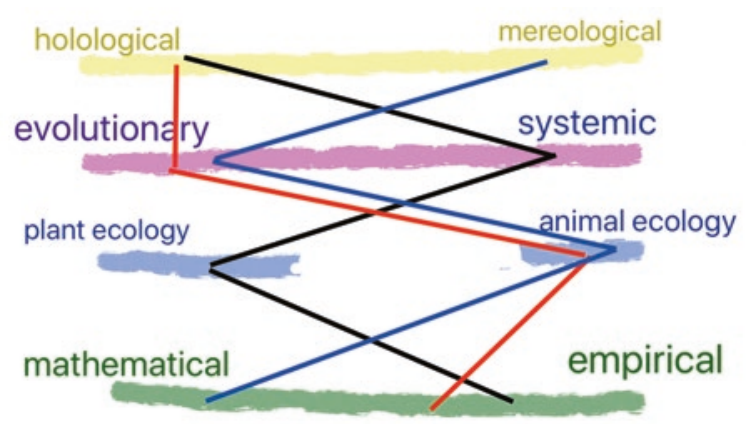


Broadly speaking, evolutionary biology and ecology have complex relationships (McIntosh 1986, pp. 256-263; Collins 1986; Harper 1967; Stearns 1982; Antonovics 1976; Huneman 2019). Besides its interest in explaining adaptation and evolution (phylogenetic patterns), evolutionary biology is interested in explaining the patterns of diversity and unity across diversity (i.e. homologies and analogies) that characterize extant and past taxa (as well as molecular patterns). And ecologists are generally interested, as I will argue more extensively in the following, in diversity within and across communities and ecosystems. Thus, both disciplines, at their own timescale, focus on the same explanandum, that is diversity.

Haeckel famously defined ecology as the "science of the struggle for existence", thus directly tying it to evolutionary biology to the extent that natural selection is seen by Darwinians as the key explanans and cause of evolution, adaptation and diversity. In principle, the emphasis on natural selection can be more or less strong in ecology, and this characterizes the whole field of ecological sciences: they are somehow ordered along a gradient which goes from evolutionary ecology to ecosystem ecology. At one extremity, evolutionary ecology adopts a very evolutionary viewpoint, considering ecosystems as the scene of competition, cooperation and mutualistic interactions, all occurring in evolutionary time and therefore being always dynamic. The other extremity of the continuum may be represented by most trends in ecosystem ecology, which adopts a very systemic viewpoint (sometimes akin to thermodynamics) insofar as ecosystems are open dissipative systems, more or less chaotic, dealt with in thermodynamic or statistical mechanics terms (Hagen 1992).

This divide is not the same as Hagen's distinction between mereological and holological perspectives on ecology mentioned before, since the holological view would accept an evolutionary understanding of ecology that takes communities or ecosystems as targets of selection. For instance, within a holological view echoing a Clementsian concept of community, an evolutionary parallel between communities and organisms, both being shaped by natural selection, is explicitly drawn in one of the major works on animal ecology in the mid twentieth century, namely the Principles of animal ecology written by Chicago ecologists Clyde Allee, Thomas Park, Orlando Park, Schmitt and Alfred Emerson, and praised in the American Naturalist by Dobhzansky. They say: "a community may be said to have a characteristic anatomy, an equally characteristic physiology and a characteristic heredity", therefore community is the "smallest [unit] that can be (...) selfsustained", and is precisely "a resultant of ecological selection" (Allee et al. 1949, 437).

Besides this gradient around the use of selection, which ranges across ecology, from the most systemic explanatory schemes (e.g. Odum's ecosystem ecology) to the most evolutionary understanding (e.g. Roughgarden's evolutionary ecology), ecology has been disciplinary cleaved between plant ecology and animal ecology since the 1900s. The two traditions were developed quite separately, starting respectively with the major advances of Warming (1909) and then Clements (1916) in plant ecology on the one hand, and the attempt at systematising animal ecology by Elton in the 1920s (e.g. Elton 1927), on the other hand.

Clements' idea of succession in communities, analogous to the development of organisms, was a key concept for much of plant ecology (Horn 1975; Lortie et al. 
2004). Even though the individualistic concept of community put forth by Gleason in the 30s (Gleason 1939) won over much of ecology, one can still see a difference between plant and animal ecology to the extent that the attention paid to succession and assemblages has been more prevalent in plant than in animal ecology. And as noted by Harper (1967), it is harder to track the offspring of plants and determine their reproductive success, which partly explains why evolutionary perspectives were less favoured in plant ecology than in animal ecology.

In turn, animal ecologists have been massively worried about the question of the regulation of population size, which was probably the major controversial theme of ecology in the 50s, as can be noticed in the major gathering of evolutionary biologists and ecologists at the Cold Spring Harbour Symposium in 1957, devoted to population biology. Most of the talks - by Anderwartha, Birch, Lack, Chitty, Orians, etc. were about population regulation in animal ecology. Much of this interest in regulation of population stemmed from a concern about pests. Charles Elton, a pioneer of invasion ecology, was the founder of the Bureau of Animal Populations in Oxford and one of its important tasks was pest control (see Chew (2011) on historical overview of invasion ecology, and Richardson (2011) on Elton's legacy in the field). Understanding the reasons of population regulation, population cycles and possible overpopulation was a crucial requisite for a successful control. One may argue that this context explains the difference between plant and animal ecology regarding the prevalence of the population regulation issue. ${ }^{2}$

Orthogonal to this divide between plant and animal ecology, there is an important tension between a more empirically oriented ecology and a mostly mathematical ecology (e.g. Schoener 1972). In a 1949 paper on population regulation (Solomon 1949). ME Solomon, British ecologist of the Bureau of Pest Control, noticed that ecologists are divided into two camps, one that starts from biology and generalizes, and one that builds mathematical models first and then tries to fit in the biological facts - e.g. Thomas Park's experiments on flour beetles, or perturbation experiments on populations (Smith 1952) vs. Lotka and Volterra's equations. This divide (see Kingsland 1995) still persists in various modes, as indicates the need recently felt by some theoretical ecologists to vindicate the use of mathematical theorizing (Servedio et al. 2014).

Regarding those five distinctions, each theoretical construction can be situated on each of the axes constituted by the gradient occurring between the poles of the distinction. In Fig. 13.1 I sketched the position of very influential works taken from distinct periods of the history of ecology (Allee et al.'s Treatise (1949), Nicholson and Bailey's model of host-parasite dynamics (1935), and Clements' plant ecology (1916)).

\footnotetext{
${ }^{2}$ Actually, Clements and Shelford (1939) intended to close the gap between plant and animal ecology, by applying a very general concept of community. They say: "the development of the science of ecology has been hindered in its organization and distorted in its growth by the separate development of plant ecology on the one hand and animal ecology on the other." (p.v) Ten years on and with a similar goal of systematizing ecological knowledge and providing basic principles, Allee et al. (1949), while acknowledging that principles of ecology should be general, still restrained to animal ecology for reasons of immaturity of the field.
} 
However, in the face of these various divides within ecology, someone could argue that biodiversity defines an object of investigation that crosses frontiers between traditions, paradigms, and explanatory strategies. A major issue in ecology is indeed coexistence - why is it that certain various species coexist and others not? How can they do so? It is a question in both plant ecology and animal ecology, approached from mereological as well as holological perspectives, and through mathematical or more empirically oriented perspectives as well. Community ecology is openly concerned with explaining biodiversity patterns, and biogeography enquires about species-area laws, which are patterns about how biodiversity is scattered across various kinds of areas (MacArthur and Wilson 1967). However, even functional ecology gives a key role to diversity (Loreau 2010), at least under the mode of "functional diversity", namely the differences between species partitioned according to equivalence classes defined by ecological functional roles (producer, nutrient cycler, etc.) (Dussault and Bouchard 2017).

In addition, the emergence of the word 'biodiversity' in the 1980s could also indicate that there is an object proper to ecology here. In the following I shall focus on the explanatory logics of diversity in ecology, in order to assess (and eventually infirm) the hypothesis that biodiversity constitutes a shared object amongst various ecological theories and traditions, and that its concept could help define a unifying framework for ecology.

\subsection{The Explanatory Reversibility of Diversity}

Many ecologists' researches indeed focus on diversity. They range from very general questions about what causes diversity in general - Hutchinson asking "Why are there so many animals?" (Hutchinson 1961)-, to questions about the way diversity is distributed locally and regionally - species-area laws in biogeography, and the mathematical models explaining them in McArthur and Wilson's Theory of Island Biogeography (1964), species abundance distributions in community ecology, or the patterns of succession of plant species in communities (as illustrated in Clements' works), as well as questions of medium degree of generality about how it is possible that many species coexist generaliter. One could view all these questions as various modes of an overarching coexistence question: how is coexistence (amongst diverse species or organisms) possible and realised at various scales?

Besides explaining diversity under its various modes, ecology is concerned with biodiversity in another and very different way. A longstanding debate in ecology regards what has been labelled the "diversity-stability hypothesis" (Ives and Carpenter 2007; Pimm 1984). Simply put, it is the claim that diversity - especially species richness - begets stability (mostly in the form of the constancy of species abundances). The more species an ecosystem includes, the more stable it seems to be (namely, it contains the same species for a long time, with abundances fluctuating around a steady means). In this sense tropical forests, which are species rich ecosystems, have been providing examples of this pattern for many decades. The 
intuition of this fact was very robust, but its explanation has been overlooked for a long time.

However, in 1974 when Robert May started to investigate this hypothesis mathematically, by modelling networks of species and increasing the diversity value, it turned out that diversity does not beget stability but on the contrary prevents it (May 1974). Assuming that a system which is "stable only within a comparatively small domain of parameter space (...) may be called dynamically fragile", clearly "such a system will persist only for tightly circumscribed values of the environmental parameters" (May 1975). The result of May's models is that a "wide variety of mathematical models suggest that as a system becomes more complex, in the sense of more species and a more rich structure of interdependence, it becomes more dynamically fragile". (ib.) Researchers then tried to address this gap between these mathematical models and some data that tended to show a stability-friendly effect of diversity. The question of stability then became: what does explain the fact that some empirically attested diversity does not conform to May's mathematical models?

Ecological stability is actually a crucial issue for theoretical reasons. After Darwin's revolution, Linnaeus' explanations for stability (namely, each species fulfills a role in a well-balanced nature; see Pimm 1993) were no longer possible, and, inversely, the constancy of ecosystems constitutes a challenge if the world is an ever-changing Darwinian world led by competition. Ecological stability is also challenging for practical reasons, since understanding what makes ecosystems robust could allow us to manage and protect them. (In fact, almost since its beginnings scientific ecology has been concerned with the damages inflicted by human industry and agriculture to natural ecosystems and ultimately to the environments in which human societies live).

Diversity is therefore a two-faceted concept: it is a major explanandum for ecology under various guises, but when the question concerns the stability of ecosystems, diversity becomes an explanans. We witness here a major epistemological feature of evolutionary and ecological questions, namely the "explanatory reversibility" of key concepts. Some concepts may indeed be the explanandum in some contexts and the explanans in others, and this reversibility attests to their theoretical significance. In evolutionary biology, notions such as plasticity (Nicoglou 2015), robustness (Wagner 2005; Huneman 2018) or mutation rates display this epistemic feature, which was first recognised by Fisher in connection with some major properties of the genetic system (dominance, recessivity, etc.) that condition evolution and are at the same time a product of past evolution (Fisher 1932).

In the field of ecology, diversity constitutes one of the concepts whose epistemic profile displays such reversibility. In the following I will explore this reversibility in more detail, and examine the role it may play in the structure of ecology. 


\subsection{Diversity as an Explanandum: Conceptual and Historical Aspects of the Ecological Coexistence Issue}

From the early times of ecology, diversity as an explanandum has been understood as a question of coexistence. I shall recapitulate this matter, and then consider a theoretical framework used to address it, namely the concept of ecological niche and its formulation by Hutchinson. I shall then turn to rival conceptions, mostly structured today around the idea of a "neutral theory". In each case, I will emphasize the aspects of the concept of biodiversity that are prominently addressed in each explanatory scheme.

The coexistence question may be arguably one of the key issues handled by ecologists since the early twentieth century. For decades, plant ecologists have embraced Clements' concept of community, which is slightly like an organism and displays a process of succession analogous to the development of an organism. ${ }^{3}$ Clements and the animal ecologist Sheldon in Bioecology (1939) generalized this idea to plant and animal communities. Allee et al. (1949) major treatise on animal ecology took the concept of community on board - i.e. "the natural unit of organization in ecology" (437) - as well as the parallel between organisms and communities, since like Clements they consider communities to have a "metabolism". Their question here is about explaining the composition rules of an assemblage of species in a given community, and whether there are laws governing these species' procession.

However, in the 40s and 50s, the coexistence question seemed to be supplanted by a different issue, i.e. the explanation of population regulation: why does a population of a species generally fluctuate over a specific abundance, with regular cycles? From Elton (1927) to Hutchinson (1957) at least, the regulation issue was the other major problem for ecologists, especially animal ecologists - with, as mentioned above, a practical concern for invasions and pest control. To some extent, the regulation issue was more mathematically tractable than that of coexistence, as attested in the seminal models by Lotka and Volterra (Volterra 1926) and by Nicholson and Bailey (1935), which mostly deal with two or three species. Nicholson and Bailey explicitly acknowledged that handling many species would require very sharp mathematical skills $(1935,597)$.

Yet, when Hutchinson (1957) formulated his influential concept of niche as a hyperspace of environmental parameters in which a subspace of the hyperspace defines the viability conditions for a species, the coexistence question came again at the center of theoretical ecology. ${ }^{4}$ At the time, such question was often traced back to an appeal to some form of group selection, as exemplified by Allee et al. (1949) animal ecology treatise and shared by many ecologists, as indicated above (see

\footnotetext{
3 "Development is the basic process of ecology, as applicable to the habitat and community as to the individual and species." (Clements and Shelford 1939, 4)

${ }^{4}$ See Pocheville (2015) for a conceptual history of 'ecological niche' that relates Hutchinson to earlier views by Grinnell and Elton.
} 
Mitman (1988) on these ideas of collectives and group selection). Coexistence in a community could be thought along the same lines as organismic integration, given that natural selection - individual in the latter case, collective in the former case underlied both systems and their cohesiveness. David Lack's work on clutch size (Lack 1947, 1954) however progressively provided powerful arguments to think that individual natural selection, and not group selection, was the reason of population regulation, and a little bit later the idea of group selection met the devastating critique issued by Williams (1966). All this made the group selection approach to the coexistence question harder in principle. Hutchinson's idea of niche to some extent thereby set the frame for more fruitful approaches to various modes of the coexistence question.

More precisely, Hutchinson published his conception in the "Concluding remarks" to the 1957 Cold Spring Harbour Symposium, where prominent ecologists and evolutionary biologists debated population ecology and mostly the regulation issue. ${ }^{5}$ The volume was a final landmark in the debate over competition-centered (inspired by Nicholson (1933) initial model of regulation by density-dependent factors, and mostly represented by Lack (1954)) and density-independence-centered explanations of population regulation that emphasized factors such as climate (Anderwartha and Birch 1954). ${ }^{6}$ Hutchinson's view of the niche followed his assessment of the debate, which tried to fairly acknowledge some epistemic value in both positions - mainly Lack's view of density-dependent regulation by competition and Anderwartha and Birch (1954) view of regulation by density-independent factors.

This concept of niche was used by Hutchinson to make sense of the role of competition in the regulation process. But more importantly, it also allows a grasp on the coexistence issue. Here, what explains coexistence is indeed the fact that first, each species has a "fundamental niche", and second, that the portion of a fundamental niche shared by two species will be exclusively inhabited by the best competitor (Fig. 13.2). "Fundamental niches" once restricted by the process of competition so, finally, natural selection - yield the "realised niches", which explain where a species will actually be found in the environment. In a classic study, Joseph Connell (1961) studied two species of barnacles, Balanus balanoid and Chtamalus stemallus, which have a stratified distribution along the coast of Scotland. The Balanus live on the border between see and rock, while the Chtamalus live just above it (Fig. 13.3a). Balanus cannot really live much higher because they cannot resist dessication during low tides. But if we take out the Balanus, the Chtamalus now appear to occupy also the space inhabited by the Balanus, in addition to their known territory (Fig. 13.3b). Thus, the fundamental niche of Chtamalus is the whole region of the rocks on which Balanus and Chtamalus live, but their realised niche is the territory where one finds them along with the Balanus, because the latter are a better competitor and wash Chtamalhus away from this portion of their fundamental

\footnotetext{
${ }^{5}$ On Hutchinson's work and influence on ecology see Slack (2010).

${ }^{6}$ Collins (1986) and Huneman (2019) argue that this episode was indeed instrumental in introducing the evolutionary viewpoint in ecology.
} 
Fig. 13.2 Realised and fundamental niches (the circle dots species is a better competitor than the crosses species) (Hutchinson (1957))

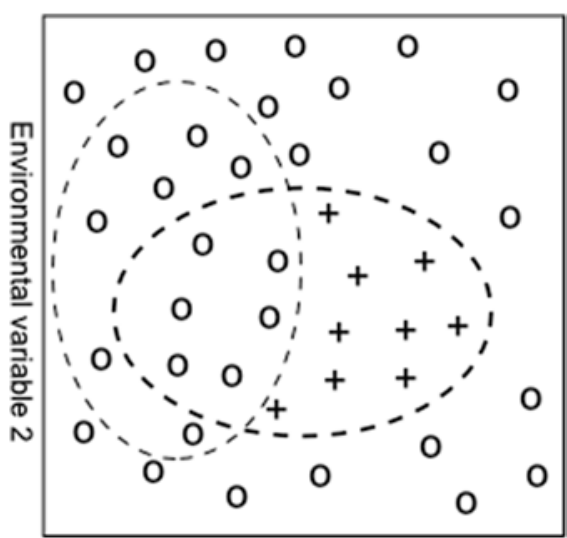

Environmental variable 1

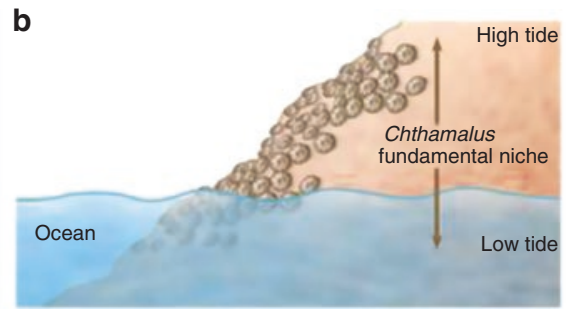

Fig. 13.3 (a) Coexistence of Balanus and Chtamallus. (b) When Balanus are taken out, Chtamalus reveal their fundamental niche by occupying it

niche. Partitioning the total environmental hyperspace into realised niches through the competitive exclusion principle eventually explains coexistence. The basic idea is that similar species cannot coexist for a long period of time, so one of them ultimately restricts the realised niche of the other: this idea yields a family of "limiting similarity" theories of coexistence that have been elaborated since the 60s. "The generalization (..) that two species with the same niche requirements cannot form mixed steady-state populations in the same region has become one of the chief foundations of modern ecology." (Hutchinson 1957)

As Hutchinson noticed, this theoretical tool is however not able to wholly explain coexistence. The "paradox of plankton", as he himself formulated (Hutchinson 1961), is the fact that while the hyperspace of environmental parameters in the ocean is very small, since there are few parameters (light, $\mathrm{pH}$, temperature, etc.) distributed over a small range of values, thousands of plankton species exist instead of a few ones as predicts the theory of the niche. Hutchinson considered various accounts to explain this, especially the view that in reality the parameter values vary at the same time as the competitive exclusion process operates, which entails that the equilibrium partition of the niche hyperspace predicted by the 
principle of competitive exclusion cannot be reached, ${ }^{7}$ and many more species actually exist.

The niche theory elaborated by Hutchinson has been crucial to address the coexistence issue. Hutchinson (1957) used it to explain why there are so many animals: the huge variety of plants, on which animals feed, makes for a very large hyperspace for possible animals, and hence many realised niches and species. But another crucial ecological aspect is the distribution of species abundances, which is not taken into account by Hutchinson's theory. As seen by Fisher and then Preston in the 30s, the species abundance distribution (SAD) seems to realize constant patterns, which can be expressed by either a lognormal curve (Fisher et al. 1943) or a logseries (Preston 1948). Witnessing such a regularity in SADs, across various kinds of ecosystems on the planet, raised the question of explaining such patterns. Consequently, theories of coexistence approached by limiting similarity elaborated since the $60 \mathrm{~s}$ have been refined to understand such patterns of biodiversity as SADs. A most recent elaboration of this theory is called the $\mathrm{R} *$ theory. Stemming from MacArthur and Levins (1967) paper on patchy environments and the competition between species foraging a finite set of identical resources heterogeneously distributed, and later developed by Tilman (1982), this theory asserts that "when resources are heterogeneously distributed, the number of species can be larger than the number of limiting resources, thereby resolving Hutchinson's paradox of the plankton. $\mathrm{R}^{*}$ theory is a conceptual advance over previous phenomenological-competition theories, such as the Lotka-Volterra predator-prey model, because it predicts the outcome of competition experiments before they are performed." (Marquet et al. 2014).

Biodiversity as an explanandum means more than the coexistence question and SAD patterns (see e.g. MacArthur 1972). In fact, another pattern discovered by ecologists carrying out censuses (especially on plants) was about the relation of surface area and species number. Called "species-area law", this was also a major pattern to be explained. In the seminal book by MacArthur and Wilson, Theory of Island Biogeography (1967), the authors recognise that the distribution of species is a major explanandum. However, their aim consists in switching from the "natural history" of species, which is mostly collecting patterns of those distributions, to a mechanistic explanation (more on this below). Theory of Island Biogeography starts by elaborating the "inland-island model". Islands are small territories separated from one another by the sea, and all of them are at some distance from the inland. The inland constitutes a reservoir for species. Individuals of those species colonise islands, but the chances of colonizing an island depend both on the distance of inland to $\mathrm{X}$ and on the size of $\mathrm{X}$. The mathematical model therefore intends to

\footnotetext{
7 "At any point the illuminated zone of the ocean or a lake the phytoplankton is normally quite diversified. There is no opportunity for niche specialization and the fundamental trophic requirements of all forms will cause them to draw on the same food supply. Such population cannot therefore represent equilibria, but since in general the plankton, though continually changing, remains in a highly diversified state, one can only suppose that the direction of competition is continually undergoing change with the progress of the seasons and concomitant thermal and chemical changes in the water and that no opportunity for the establishment of a single species equilibrium condition ever occurs." (Hutchinson 1959)
} 
explain varieties of species-area laws on the basis of these three parameters: island size, amount of islands, distances to inland.

Theory of Island Biogeography uses a hypothetico-deductive model-based method: like Fisher or Kimura's population genetics, it starts by building models and then considers how data and patterns fit to the model. Theory of Island Biogeography also works at a higher scale than community ecology. "Islands" of course are theoretical entities, not physical islands; they correspond to territories that are poorly communicating genes and organisms to other territories: they can be valleys, forest patches, etc. (Island biogeography has theoretical affinities with the concept of "metapopulation" elaborated at the same time by Richard Levins (1969)).

Noticeably, most of Theory of Island Biogeography considers the dispersion and colonisation of species and not the relative fitness differences between individuals. Hubbell $(2001,2006,2010)$ will consider this as the first "dispersal assembly" model of coexistence, and will contrast it with the "niche assembly" models deriving from the limiting similarity theory (Leigh 2007). His own theory, called the "neutral unified theory of biogeography and ecology" (Hubbell 2001), intends to elaborate a dispersal assembly model, which is therefore 'neutral' in the sense that, like Kimura's evolutionary models (Kimura 1985; He and Hubbell 2005), there is no fitness differences between elements (alleles for Kimura, species for Hubbell). His model integrates both regional and local community scales, and therefore allows to explain species abundance distribution as well as species-area laws. The key change for his theory (as compared to Theory of Island Biogeography) is that the neutrality assumption, called "ecological equivalence", is defined in terms of per capita birth and death rates rather than in terms of species fitness (as McArthur and Wilson were doing) (Munoz and Huneman 2016, Hubbell 2005; Purves and Turnbull 2010). It met predictive success: "It was surprising to find that spatial neutral models give rise to frequency distributions of precision that are very similar to those estimated from biological surveys, as a consequence of the spatial patterns produced by local dispersal alone" (Bell et al. 2006) - which concerned several kinds of communities (see McGill et al. 2006): plants, coral reefs or fish (Muneepeerakul et al. 2008).

Thus, a major divide in contemporary community ecology is today defined by the meaning ascribed to the neutral theory: whether ecologists follow Hubbell in considering that it is a good theory for biodiversity (Bell 2000), especially because it has far less parameters than the rival $\mathrm{R}^{*}$ theory (Marquet et al. 2014), or think that the niche paradigm is still the best explanation since neutral models are not explanations (see amongst others Chave 2004; Hubbell 2005; Holt 2006; Allouche and Kadmon 2009; Leibold and McPeek 2006; Doncaster 2009; Rosindell et al. 2011). Without delving into the controversy, it has to be noted that the neutral theory appears as a unified, scale-encompassing theory of biodiversity while the limiting similarity paradigm proposes explanations that are generally different for several aspects of coexistence (species abundance distribution, species area laws, etc.) (Huneman 2017). 
In all those theories, the explanandum is a range of patterns of coexistence that are defined mostly in terms of species diversity, and often the species richness is the major aspect - even though species abundances are also taken crucially into account in SADs.

But what happens if we turn to diversity as an explanans?

\subsection{Diversity as an Explanans}

In this section, I will consider the so-called diversity-stability hypothesis and the particular notions of diversity that have been involved in the attempts to clarify, formulate and test this hypothesis for four decades. I will first consider approaches that focus on the way diversity as species richness is organized through interactions in ecological networks; then I shall turn to the notions labelled "functional diversity" and "phylogenetic diversity".

The diversity-stability hypothesis has been for a long time an assumed but unproven hypothesis, evidenced by many observations - somewhat like famous mathematical conjectures that are not proven but seem established by the behaviours of known numbers. As Orians writes, "The belief that natural ecosystems become more diverse and, hence, more stable with time after a disturbance is widely accepted and regularly repeated in ecology textbooks (...) the correlations, not to mention causations, are still obscure." (Orians 1975, p. 139) Indeed, Orians notices that even the correlation between diversity and stability could not exclude that such a common cause as environmental constancy yields both. ${ }^{8}$

To this extent, the real meaning of the terms involved (which diversity? what stability?) was not really investigated. ${ }^{9}$ Thus, as indicated above, May's mathematical findings that diversity per se, crudely defined as the number of species interacting in an ecosystem, does not beget stability, triggered a reflexive turn in the study of diversity as a stability-promoter. ${ }^{10}$

Robert May's results were in fact showing that an ecosystem with randomly interacting species is less stable - in the sense of constancy of species' abundances while the amount of species increases. Yet some evidence of a stability-begetting effect of diversity existed in the field, as stated, for example by McNaughton (1977): "The weight of evidence resulting from explicit tests of the diversity-stability hypothesis (...) suggests, not that the hypothesis is invalid, but that it is correct".

\footnotetext{
8 "Environmental constancy facilitates diversity while reducing perturbations that might affect stability" (Orians 1975, p. 139)

9 "The concepts are normally discussed with poorly defined terms, reflecting an uncertainty about what concept(s) of stability are useful in ecology" (ib.)

${ }^{10}$ Notice that the regulation issue, arguably another key issue of theoretical ecology, also concerns an aspect of stability, since it is about the steadiness of one species population abundance. Therefore, the diversity as explanans is involved in the other major question of ecology, provided one assumes that the key questions are regulation and coexistence.
} 
Thus, ecologists then enquired about what aspects of diversity were in those cases accounting for this effect. First, in contrast with May's models, the connections in an ecological network are often not random. It may be that many predators have only one prey, for instance, and that a few superpredators have many preys. In any case, few ecosystems are such that species have an even chance of having a given number of preys or predators. Thus, the question switched towards the identification of the properties of ecological networks that would be such that increasing diversity would increase stability. Given a fixed degree of diversity as species richness, many networks are possible: a first rough characterization of their differences is their particular value of connectance, namely, the ratio of the amount of realised connections (here, interactions) between species to the total amount of possible connections.

More generally, a perspective on the question of the role of ecological diversity in stability is the general investigation of topological properties of graphs realised by ecological networks of interactions. Diversity, as species richness per se, does not increase stability but some network topologies make it likely to promote stability: this hypothesis supports the general move towards an investigation of ecological networks and their role in stability (Solé et al. 2002; Dunne 2006; Dunne et al. 2002; Kéfi et al. 2016). Some of the results emphasize the key role of species networks topologies in guaranteeing some stability. Scale-free networks, in which the distribution of the degrees ${ }^{11}$ of the nodes follows some power law, ${ }^{12}$ are stable because this topology entails a very low probability for a random species extinction to reach one of the hubs of the network and hence alter the overall structure, and ultimately the functioning of the community (Solé et al. 2002). This probability becomes lower with the increasing size of the network, i.e. with the increase in species richness.

Small-world structures ${ }^{13}$ of ecological networks, when they are realised, also beget stability. This is because the high clustering coefficient means that the overall pattern of interaction is mostly preserved if some cluster in the network is altered. On the other hand, the short path length means that a species which loses its privileged interacting species in its neighbouring cluster can still be related to its other interacting species via the other species in its network, to which it is highly connected (Strogatz 2001; Solé and Goodwin 1988). In this case, similarly, increasing

\footnotetext{
${ }^{11}$ In a given network, made up of nodes (or vertices) and edges that connect some nodes, the "degree" of a node is the amount of edges on this node.

${ }^{12}$ Intuitively, there are a few nodes with many connections (they will be called hubs), slightly more hubs with a bit less connections, and so on, and a large majority of nodes with only very few connections. Formally speaking, the number of nodes of degree $n+1$ will be $1 / 10$ the number of nodes of degree $\mathrm{n}$. (Or any mathematically power law of the same kind). Wealth in human societies is known to follow power laws; and one frequent generating process for power law nodes distributions is the "preferential attachment", namely, the probability of having a new connection is proportional to the extant amount of connections. Sometimes called "rich get richer", this process is clearly instantiated by financial mechanisms (Albert and Barabasi 2002).

${ }^{13}$ Small-world is a kind of network characterized by the fact that it is highly clustered (a cluster being a set of nodes more significantly connected between themselves than to other nodes) and at the same time has a short path length (the path length being the average number of edges between two randomly taken nodes) (Watts and Strogatz 1998).
} 
the amount of species, hence the size of the network, strengthens this stabilityenhancing property.

May's counterintuitive findings about stability not yielded by diversity in general are therefore corrected or supplemented by those network analyses of the topology of ecological network; however, it is not clear exactly what is meant in both cases by "stability". Thus, the meaning of "stability" in all these models had to be questioned. As Tilman (1994) made clear, even if species richness does not, in theory, beget stability as constancy of species abundances, it has a positive effect on the constancy of biomass of an ecosystem. That is clearly another meaning of "stability", which relies on diversity. And early on, Holling (1973) had introduced "resilience" understood as the ability of an ecological system to restore its key parameters after a perturbation. Resilience has various modes and can be empirically measured. Moreover, "persistence" named the fact that an ecosystem does not "lose" a species, even though the abundances of all species vary a lot and do not come back to the initial state.

Yet, notions of stability are themselves even more numerous than that and it not even clear if there is one overarching meaning. Orians (1975) distinguishes: Constancy - "a lack of change in some parameter of a system, such as the number of species, taxonomic composition, life form structure of a community, or feature of the physical environment"; Persistence - "the survival time of a system or some component of it"; Inertia - "the ability of a system to resist external perturbations"; Elasticity - "the speed with which the system returns to its former state following a perturbation" (which is similar to Holling's resilience); Amplitude - "the area over which a system is stable"; Cyclical Stability - "the property of a system to cycle or oscillate around some central point or zone"; Trajectory Stability - "the property of a system to move towards some final end point or zone despite differences in starting points". (Fig. 13.4) Stability, in other words, depends on the kind of perturbations one considers, and for Orians, in addition, all measures should be related to fitness: "For these relationships to be insightful, perturbations [or perturbation types] should be related to the evolutionary histories of the organisms experiencing the perturbations, and measured in terms of the total investments that must be made to increase or maintain fitness during those perturbations." (ib. p. 143) This indicates a bias in favor of evolutionary approaches to ecology, which may not be found in other theories of stability, especially when one turns to functional or ecosystems ecology.

In any case, the question of which diversity begets stability, and how it is possible that a certain diversity begets a certain stability, presupposes that one clarifies which stability is at stake. Not all diversity properties are likely to beget the same stability property. ${ }^{14}$

Of course, the ecological networks can be understood also from the perspective of their dynamics (Ulanowicz 1983; Szyrmer and Ulanowicz 1987), and especially

\footnotetext{
${ }^{14}$ On the various meanings of stability in ecology, and the possibility of formally making sense of some of them in the context of phase spaces, attractors and measures of Lyapounov exponents, see Justus (2008).
} 


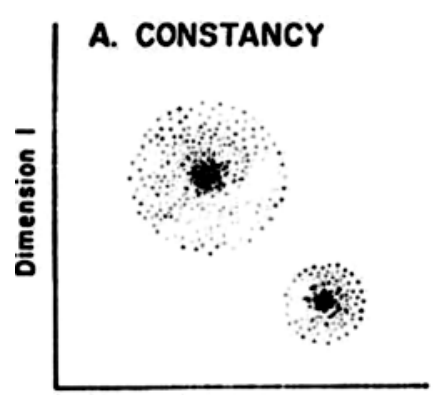

Dimension 2
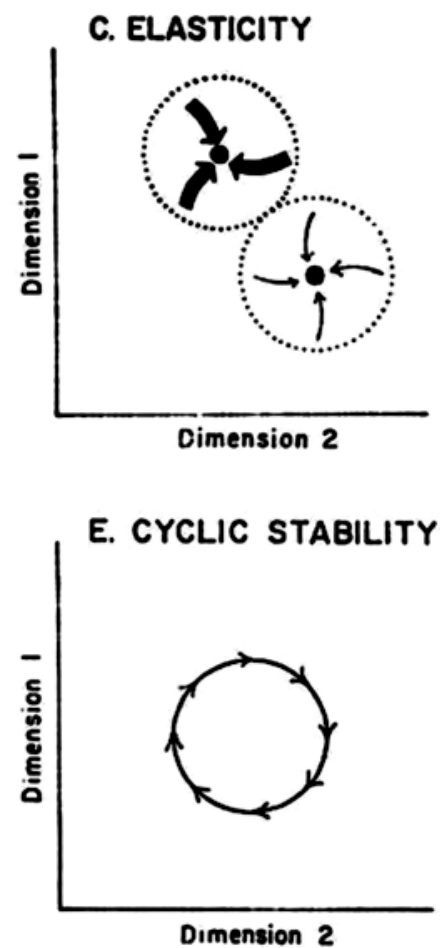

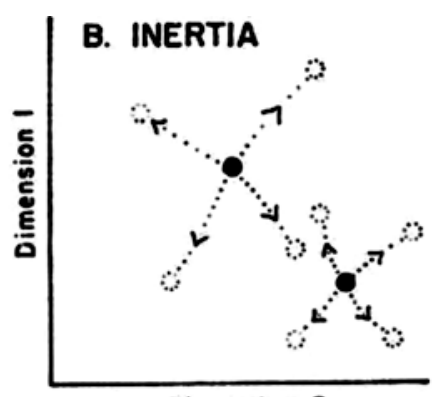

Dimension 2

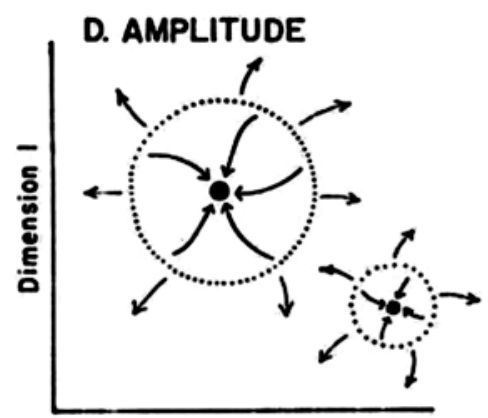

Dimension 2

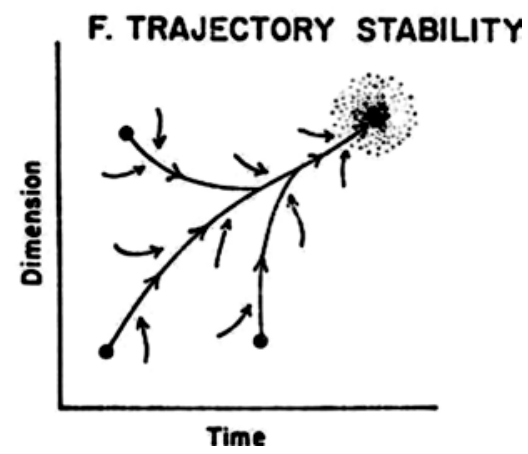

Fig. 13.4 The six kinds of stability in ecology. (After Orians 1975)

by considering not only the constraints put by the topology on the possible dynamics (Huneman 2015), but also, by capturing the major behaviours of the dynamics of fluxes within the networks and the possible evolution of the networks likely to follow (Ulanowicz 1986). This approach is perfectly compatible with a functional ecology that would consider ecosystems as open thermodynamic systems and model their inner behaviour, such as what Odum (1953) theorised. It allows researchers to understand the role that increasing diversity (as species richness) plays in the productivity of ecosystems, or ecosystem functioning, or some key features of ecosystem functioning. 
The network perspective is not the only way to capture the possible contributions of diversity, mostly as species richness, to stability, or to some aspects of it. Functional ecologists started to define "functional differences" understood in terms of functional roles of a species played in an ecosystem (Blandin 2014). From this perspective, two species can be biologically different but functionally equivalent. Such functional diversity may be likely to play a role that species diversity cannot play in the emergence and maintenance of some stability. However, functional diversity and species richness are not wholly orthogonal. As Tilman (1996) argued, species diversity induces a lot of microscale environmental heterogeneities, which in turn allow for a wide variety of ecological roles. But this connection is just plausible and does not allow one to always consider species richness as a proxy for functional diversity.

Experiments have recently confirmed the stability-enhancing role of functional diversity. The bumphead parrotfish Bolbometopon muricatum is the largest parrotfish in the oceans and is considered a keystone species in the coral reef (Huey and Belwood 2009). It is a major target for fishermen (and hence an imperilled species) but is also heavily consuming reef substrate: "the most conspicuous and perhaps most powerful effect $B$. muricatum has on reef ecology is delivered via individuals' intense direct consumption of reef substrate." (McCauley et al. 2014)

The experimental change of this parrotfish to another parrotfish, or the reintroduction of other parrotfish species after its removal, show that the equilibrium of the coral reef is threatened. Species diversity in this case is not changed (Bellwood et al. 2003). But given that the functional role of the bumphead parrotfish is unique, it follows that functional diversity is decreased while species richness remains constant. In this case functional diversity, and not species diversity, is what contributes to ecosystem stability.

Functional diversity seems thus to positively relate to productivity and stability of ecosystems. However, as argued by Cadotte et al. (2009) "functional group richness is a problematic measure for two reasons. First, the removal or addition of "functionally redundant" species may have effects on community dynamics and processes, indicating that there are important functional differences not captured by broad groupings. (...) The second reason is that functional group richness tends to predict only a limited amount of variation in productivity and may even explain less variation than having randomly assigned groups."

Thus, more recently ecologists have started to consider phylogenetic diversity and its role in ecosystem functioning and conservation biology, under the name of "ecophylogenetics". Here, phylogenetic diversity is understood as "the amount of evolutionary history represented in the species of a particular community", and "commonly used measures of phylogenetic diversity are the total branch length of a phylogenetic tree that contains all species present in a community, or the sum of pairwise distances between species weighed by their relative abundances." (Mouquet et al. 2012) Ecologists found, for instance, that plant productivity is enhanced in communities with phylogenetically distantly related fungal species compared to closely related species. "This result suggests, under the hypothesis of a strong phylogenetic signal of the traits considered, that the loss of an entire lineage could have 
strong negative ecological consequences since distinct lineages are likely to perform different functions." Thus, to this extent one can use phylogenetic diversity "as a proxy of unmeasured functional diversity for the purpose of assessing its connection to ecosystem functioning" (Mouquet et al. 2012).

The three diversities, species richness, phylogenetic diversity and functional diversity, are in general quite decoupled. This is manifest in a study by D'Agata et al. (2014) on the human impact on biodiversity loss in coral reefs. In the reef area, human density varies on a gradient spanning from 1,7 to 1720 inhabitants $/ \mathrm{km}^{2}$. The researchers investigated the effect of this density upon the three biodiversities. It turned out that the impact starts to be sensible at a threshold of around 20 inhabitants $/ \mathrm{km}^{2}$; however, the effect is very different regarding each kind of diversity. Considering the extreme impact, at 1705 inhabitants $/ \mathrm{km}^{2}$ the effects are: on species richness: $12 \%$; on functional diversity: $46 \%$; on phylogenetic diversity: $36 \%$. Thus, first, species richness is a very bad predictor of human impact on biodiversity loss and should be not used as an indicator for coral management, one should prefer functional and phylogenetic biodiversity instead; second, the slope of the impact after the threshold, on each diversity, is significantly different, therefore they cannot be taken as proxies for each other (Fig. 13.5).

Fig. 13.5 Differential effects on human density in three kinds of biodiversity. (After D'Agata et al. (2014))
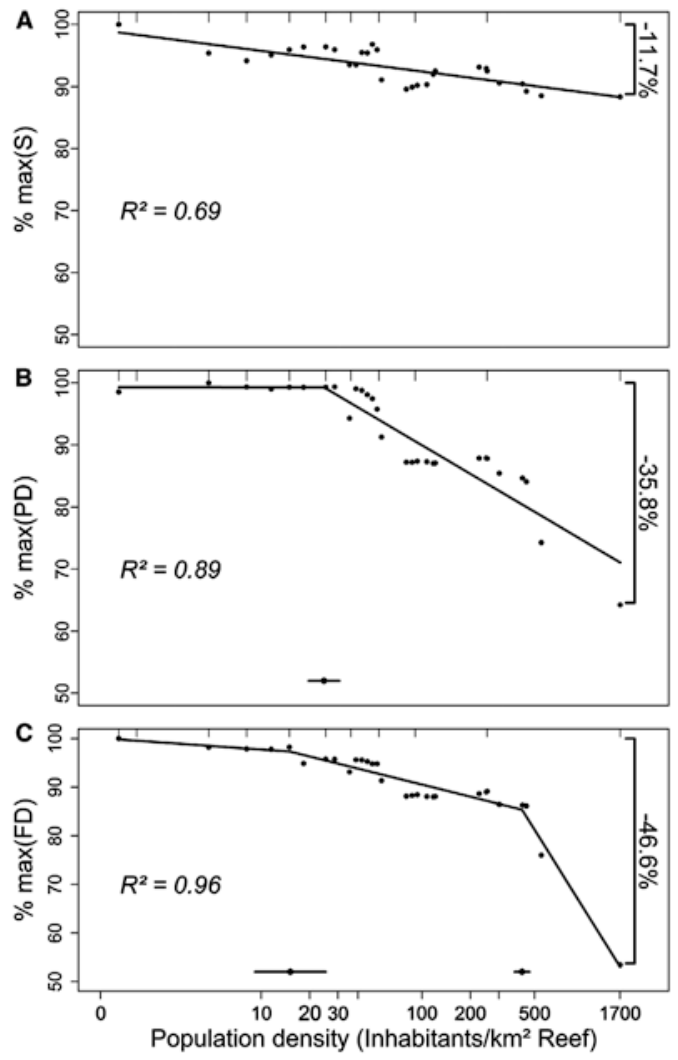
To sum up, diversity as an explanans is diffracted into several concepts of diversity such that each plays, within different explanatory perspectives, a specific explanatory role regarding productivity, stability and other ecosystem functioning aspects. Those diversities are not translatable and are in general weakly correlated, even though locally under some conditions they can be quite aligned.

It seems therefore that the explanatory reversibility of diversity includes a gap between the explanandum and the explanans, since the explanandum is mostly concentrated upon species richness, unlike the explanans. In turn, the explanandum is instantiated in various patterns of biodiversity that may link space and diversity, while the explanans generally does not include biodiversity patterns (or at least the same biodiversity patterns: SADs, species-area distributions etc.). Two general conclusions can be drawn here: as an explanans, ecological diversity is much more diffracted than as an explanandum; and the explanatory reversibility of the concept is not transparent, complete or univocal.

One can usefully compare this explanatory reversibility to the explanatory reversibility of robustness in evolutionary biology. Here, robustness, understood either as a capacity to function notwithstanding disturbances, or as an ability to maintain a set of functions in a very wide range of circumstances (Kitano 2004) also covers distinct meanings. Especially, the two key types of robustness for evolutionary biologists are "mutational robustness", as a robustness defined with regard to genetic mutations, and "environmental robustness", as a robustness defined with regard to environmental changes (de Visser et al. 2003). Biologists debate about whether one has been the effect of the other, and then, given that robustness is a very general property of living systems at all levels (Wagner 2005), they ask two kinds of questions: what made robustness evolve (robustness as an explanandum)? What does robustness do in evolution and how does it affect it (robustness as an explanans)? But such explanatory reversibility of robustness (Huneman 2018) is such that the two types of robustness are together considered, both, in the explanans side and in the explanandum side. This is not the case with the biodiversity concept in ecology. In the last section, I shall attempt to account for the structure of the concept of diversity in a way that will make sense of this specific explanatory reversibility of the concept. Ultimately, this will decide upon the role of "biodiversity" as a crucial concept for unifying ecology.

\subsection{A "Conceptual Space" Approach to the Diversity Concept}

What do I mean when I say that some $\mathrm{X}$ - a community or an ecosystem - is more diverse than Y? Does it include more species, or species more diverse, or more functionally diversified, or is $\mathrm{X}$ phylogenetically more extended on the tree of life than $\mathrm{Y}$ ?

No principled way exists to answer this question. One could be tempted to say that there is no objective answer at all. However, another approach consists in saying that there are many objective facts enveloped in a judgment about $\mathrm{X}$ being more 
diverse than $\mathrm{Y}$, and that the concept of biodiversity is then in each case built or constructed upon this set of objective facts. Various answers to the question are then yielded by various ways of constructing this concept of biodiversity.

Such an approach could be developed in the following terms: consider each of the properties used to construct biodiversity indices and to measure biodiversity as axes in a hyperspace. Species richness would obviously be one, as would then be species evenness, disparity, species abundance, phylogenetic distance, functional differences. Those axes describe facts about each community or ecosystem that can be objectively measured: the number of species at the local scale, their abundances, the functional redundancies or the amount of the phylogenetic trees covered by the species in a community or metacommunity are not in the eye of the beholder, they can be settled independently of epistemic preferences, explanatory strategies or methodological choices (or, at least, their objectivity is not different or less objective than generally establishing facts in science). Thus each community or ecosystem occupies a point (or a small neighbourhood, considering that the values evolve in time) in this space, defined by how much it scores on each of these axes (Fig. 13.6). Functional diversity is the projection of this point on the axis "functional diversity"; same for phylogenetic diversity; etc.

But of course each axis may not be as important as the others regarding a given diversity measure - for instance, some concepts of diversity used in conservation biology would overtone functional diversity or species abundances; and diversity in ecophylogenetics, but also in biogeography, could overemphasise the axis of "phylogenetic diversity". Many diversity indices are indeed constructed by considering the values on

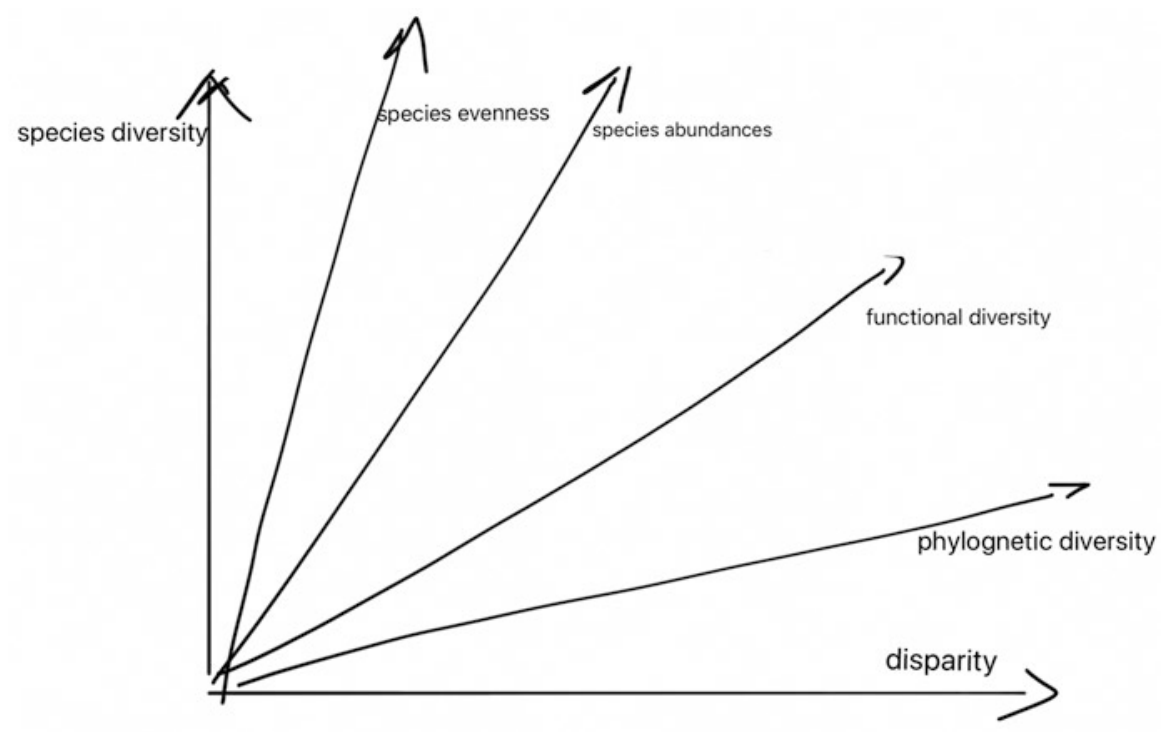

Fig. 13.6 The conceptual space of biodiversity and its axes. Notice that axes can be weighed and scaled differently in order to construct a specific biodiversity concept 
several axes but not all of them, and then by possibly weighing the various axes differently; e.g. species richness or disparity could be differently weighed. If one wants to represent in our conceptual space the way a specific biodiversity concept, and then biodiversity measure, is constructed, one could assign different scales to each axis. This plurality of choices regarding the importance, weight or scales of each axis results in a plurality of possible concepts of biodiversity. And in turn, each explanatory project in ecology regarding diversity - as an explanans, or as an explanandum will involve one (or a few) specific biodiversity concepts among this plurality.

In this approach, "biodiversity" appears as a possible construction built upon the objective values that $\mathrm{X}$ (community, ecosystem) scores on various axes. Each way of constructing it, by making projections on some axes, or taking only a few axes, possibly scaled or weighed in different ways, provides a different concept of biodiversity. Each of these concepts in turn is based on objective facts, but includes some epistemic and possibly non-epistemic values that governed the construction of this concept from those facts. For instance, the biodiversity concept used in conservation may emphasize the dimension of abundance, since the probability of extinction of a species - which is in general something conservation biologists intend to prevent is inversely proportional to abundance. But the weighing of the axes here, and the overweighing of abundances, relies on the non-epistemic value of our interest in conserving species. Inversely, some biodiversity concepts used when one wants to design, maintain or maximise ecosystem services, may favor the functional diversity; here too, the reasons for weighing axes differently relies on non-epistemic values, namely our interest in flourishing ecosystem services.

Now, the explanatory reversibility of the concept of diversity can be approached in this context. Considering that biodiversity is defined in this conceptual space determined by the axes I mentioned, it appears that diversity as explanans and diversity as explanandum target different regions of this space (Fig. 13.7). According to analyses in Sects. 13.4 and 13.5, the explanans is heavily concentrated around the axes on functional and phylogenetic diversity, while the explanandum would be rather located around the axes of species richness, evenness and abundances. The overall conceptual space of diversity is therefore not identically involved in the two explanatory takes on diversity, and this characterizes the epistemic nature of such an explanatory reversibility, as compared to the explanatory reversibility of the concept of robustness mentioned above. The latter is "complete", while the former is not - in the sense that the conceptual space (respectively, of diversity and of robustness) is in the latter case completely and identically concerned by both explanatory projects, and in the former, partially and differently concerned by each explanatory project. But (unlike diversity) robustness cannot claim to be a shared and pervasive object in evolutionary biology, and therefore the "completeness" of its explanatory reversibility does not carry consequences for the question of the theoretical unity of evolutionary biology, unlike in the case of ecological diversity considered here.

This approach to diversity as a conceptual space was not only intended to provide a representation for the incompleteness of the explanatory reversibility of diversity. It is more generally intended to make sense of the fact that the epistemic status of diversity in ecology does not allow for a theoretical unity based on such 


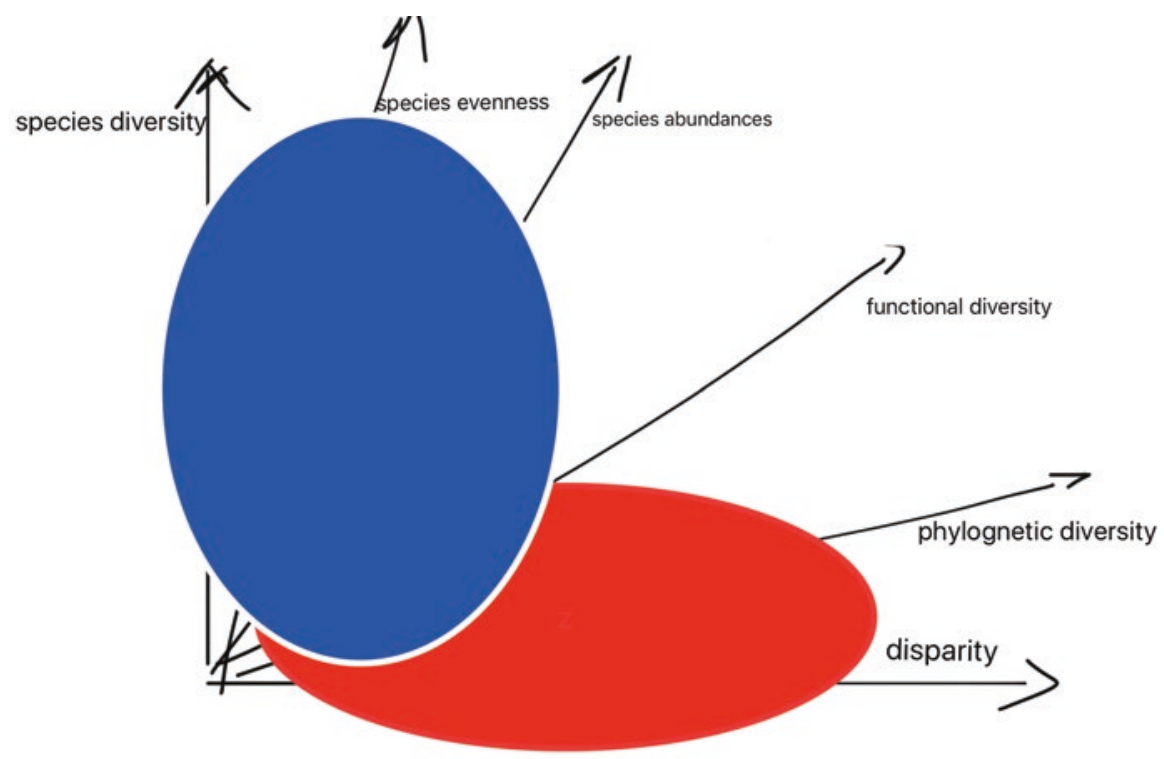

Fig. 13.7 Regions of the conceptual space of biodiversity targeted by explanatory projects: in red, when biodiversity is the explanans, in blue, when it is the explanandum (Color figure online)

concept, because various explanatory questions in ecology target different conceptual areas of this space. Thus, even though there is here some unity, due to the fact that there is one conceptual space, it is the unity conferred by a same general object. But the fact that the space is so to say differently exploited by various approaches and traditions makes it difficult to think that for this sole reason a theoretical unity can embrace all those approaches and traditions.

Through this "conceptual space approach" to diversity, one sees that diversity is not a purely subjective property, or a property that only exists is the eye of the (scientific) beholder; that many crucial explanatory projects in ecology diversely target diversity; and that at the same time, all these projects cannot be theoretically unified through this reference to diversity as something objective.

\subsection{Conclusion}

To wrap up the arguments made here, biodiversity is arguably a key issue in ecology, and many theories and explanatory strategies are concerned by it. Diversity is manifestly an explanatory reversible concept, and at first stake this could mean that it could play a role in unifying ecological theories and tools. However, because of the specific incompleteness of the explanatory reversibility of the concept of diversity, illustrated by the way in which its conceptual space is variously targeted by explanatory projects, it appears that the discourses, theories and explanatory 
strategies of ecologists could not be theoretically unified as a set of scientific approaches to diversity. Even if it is perhaps illusory to think that a single concept could unify a theoretical field, in a non-superficial manner at least, the present enquiry shows that in order to search for unifying principles for ecology, one should not start by focusing on biodiversity. Ecologists share a concern for biodiversity, but the geography of the concept of diversity is such that this shared concern cannot become a principle of unification or an essential part of a unifying strategy.

Acknowledgements I am grateful to the audience of the Urbino conference on biodiversity, organized by Elena Casetta and Andrea Borghini in 2015, where a first version of this chapter has been presented. I warmly thank Davide Vecchi and Elena Casetta, whose comments significantly improved the manuscript, as well as Matt Chew, Sébastien Dutreuil, Antoine Dussault and two anonymous reviewers. This work was possible thanks to the CNRS Laboratoire International Associé ECIEB Paris-Montréal and the GDR "Les savoirs de l'environnemental" (CNRS GDR3770 Sapienv).

\section{References}

Albert, R., \& Barabasi, A.-L. (2002). Statistical mechanics of complex networks. Reviews of Modern Physics, 74, 47-97.

Allee, W. C., Park, O., Emerson, A. E., Park, T., \& Schmidt, K. P. (1949). Principles of animal ecology. Philadelphia: W. B. Saunders Company.

Allouche, O., \& Kadmon, R. (2009). A general framework for neutral models of community dynamics. Ecology Letters, 12, 1287-1297.

Andrewartha, H. G., \& Birch, L. C. (1954). The distribution and abundance of animals. Chicago: University of Chicago Press.

Antonovics, J. (1976). Plant population biology at the crossroads. Input from population genetics. Systematic Botany, l, 234-245.

Bell, G. (2000). The distribution of abundance in neutral communities. The American Naturalist, 155, 606-617.

Bell, G., Lechowicz, M. J., \& Waterway, M. J. (2006). The comparative evidence relating to the neutral theory of community ecology. Ecology, 87, 1378-1386.

Bellwood, D. R., Hoey, A. S., \& Choat, J. H. (2003). Limited functional redundancy in high diversity systems: Resilience and ecosystem function on coral reefs. Ecology Letters, 6, 281-285.

Blandin, P. (2014). La notion de biodiversité: sémantique et épistémologie. In E. Casetta \& J. Delord (Eds.), La biodiversité en questions (pp. 31-82). Paris: Matériologiques.

Cadotte, M. W., Cavender-Bares, J., Tilman, D., \& Oakley, T. H. (2009). Using phylogenetic, functional and trait diversity to understand patterns of plant community productivity. PLoS One, 4, e5695.

CBD. (1992). Convention on biological diversity, United Nations. http://www.cbd.int/doc/legal/ cbd-en.pdf.

Chave, J. (2004). Neutral theory and community ecology. Ecology Letters, 7, 241-253.

Chew, M. K. (2011). Invasion Biology: Historical Precedents. In D. Simberloff \& M. Rejmánek (Eds.), Encyclopedia of biological invasions (pp. 369-375). Berkeley: University of California Press.

Clements, F. E. (1916). Plant succession (Carnegie Institute Pubi. no. 242). Washington, DC: Carnegie Institute.

Clements, F., \& Shelford, V. (1939). Bio-ecology. New York: J. Wiley \& Sons, Inc.; London.

Collins, J. P. (1986). Evolutionary ecology and the use of natural selection in ecological theory. Journal of the History of Biology, 19, 257-288. 
Connell, J. (1961). The influence of interspecific competition and other factors on the distribution of the barnacle chthamalus stellatus. Ecology, 42(4), 710-723.

D’Agata, S., Mouillot ,D., Kulbicki, M., Andrefouet, S, Bellwood, D., Cinner, J., Cowman, P., Kronen, M., Pinca, S., Vigliola, L. (2014). Human-mediated loss of phylogenetic and functional diversity in coral reef fishes. Current Biology, 24(5), 555-560.

de Visser, J. A. G. M., Hermisson, J., Wagner, G. P., Ancel Meyers, L., Bagheri-Chaichian, H., Blanchard, J. L., \& Chao, L. (2003). Evolution and detection of genetic robustness. Evolution, 57, 1959-1972.

Doncaster, C. P. (2009). Ecological equivalence: A realistic assumption for niche theory as a testable alternative to neutral theory. PLoS One, 4, e7460.

Dunne, J. (2006). The network structure of food webs. In M. Pascual \& J. Dunne (Eds.), Ecological networks: Linking structure to dynamics in food webs. Oxford: Oxford University Press.

Dunne, J. E., Williams, R. J., \& Martinez, N. D. (2002). Food web structure and network theory: The role of connectance and size. PNAS, 99, 12917-12922.

Dussault, A., \& Bouchard, F. (2017). A persistence enhancing propensity account of ecological function to explain ecosystem evolution. Synthese, 194, 1115.

Elton, C. (1927). The ecology of animals. New York: Wiley.

Fisher, R. (1932). The evolutionary modification of genetic phenomena. Proceedings of the 6th International Congress of Genetics, 1, 165-172.

Fisher, R. A., Corbet, A. S., \& Williams, C. B. (1943). The relation between the number of species and the number of individuals in a random sample from an animal population. Journal of Animal Ecology, 12, 42-58.

Ford E.B. (1964). Ecological genetics. London : Chapman and Hall.

Gleason, H. A. (1939). The individualistic concept of the plant community. The American Midland Naturalist, 21, 92-110.

Gosselin, F. (2014). Diversité du vivant et crise d'extinction: des ambiguïtés persistantes. In E. Casetta \& J. Delord (Eds.), La biodiversité en questions (pp. 119-138). Paris: Matériologiques.

Hagen, J. (1989). Research perspectives and the anomalous status of Modern Ecology. Biology and Philosophy, 4, 433-455.

Hagen, J. (1992). The Entangled bank. The origins of ecosystem ecology. New Brunswick: Rutgers University Press.

Harper, J. L. (1967). A Darwinian approach to plant ecology. Journal of Ecology, 55, 247-270.

Holling, G. (1973). Resilience and stability of ecological systems. Annual Review of Ecology and Systematics, 4, 1-23.

Holt, R. D. (2006). Emergent neutrality. Trends in Ecology \& Evolution, 21(10), 531-533.

Horn, H. S. (1975). The ecology of secondary succession. Annual Review of Ecology and Systematics, 5, 25-37.

Hubbell, S. P. (2001). The unified neutral theory of biodiversity and biogeography. Princeton: Princeton University Press.

Hubbell, S. P. (2005). Neutral theory in community ecology and the hypothesis of functional equivalence. Functional Ecology, 19, 166-172.

Hubbell, S. P. (2006). Neutral theory and the evolution of ecological equivalence. Ecology, 87, 1387-1398. 31.

Hubbell, S. P. (2010). Neutral theory and the theory of island biogeography. In J. B. Losos \& R. E. Ricklefs (Eds.), The theory of island biogeography revisited (pp. 264-292). Princeton: Princeton University Press.

Huey, J., \& Bellwood, D. (2009). Limited functional redundancy in a high diversity system: Single species dominates key ecological process on coral reefs. Ecosystems, 12, 1316-1328.

Huneman, P. (2015). Diversifying the picture of explanations in biological sciences: Ways of combining topology with mechanisms. Synthese, 195, 115-146.

Huneman, P. (2019). "How the Modern Synthesis came to ecology." Journal of the History of Biology. Forthcoming, 52, 4. 
Huneman, P. (2017). Stephen Hubbell and the paramount power of randomness in ecology. In O. Harman \& M. Dietrich (Eds.), Dreamers, visionaries and revolutionaries in the life sciences. Chicago: University of Chicago Press, pp. 176-195.

Huneman, P. (2018). Robustness as an explanandum and explanans in evolutionary biology and ecology. In M. Bertolaso, S. Caianiello \& E. Serelli (Eds.), Biological Robustness. Emerging Perspectives from within the Life Sciences. Dordrecht: Springer, pp. 95-121.

Huneman, P., \& Walsh, D. (Eds.). (2017). Challenging the modern synthesis: Adaptation, development and inheritance. New York: Oxford University Press.

Hutchinson, G. E. (1957). Concluding remarks. Cold Spring Harbor Symposia on Quantitative Biology, 22, 415-427.

Hutchinson, G. E. (1959). Homage to Santa Rosalia or why are there so many kinds of animals. American Naturalist, 93, 145-159.

Hutchinson, G. E. (1961). The paradox of the plankton. American Naturalist, 95, 137-145.

Ives, R., \& Carpenter, J. (2007). Stability and diversity of ecosystems. Science, 317(5834), 58-62.

Justus, J. (2008). Ecological and Lyapunov stability. Philosophy of Science, 75, 421.

Kéfi, S., Miele, V., Wieters, E. A., Navarrete, S. A., \& Berlow, E. L. (2016). How structured is the Entangled bank? The surprisingly simple organization of multiplex ecological networks leads to increased persistence and resilience. PLoS Biology, 14(8), e1002527.

Kimura, M. (1985). The neutral theory of molecular evolution. Cambridge: Cambridge University Press.

Kingsland, S. (1995). Modeling nature: Episodes in the history of population ecology (2nd ed.). Chicago: University of Chicago Press.

Kitano, H. (2004). Biological robustness. Nature Reviews Genetics, 5, 826-837.

Lack, D. (1947). The significance of clutch size. Ibis, 89, 302-352.

Lack, D. (1954). The natural regulation of animal numbers. Oxford: Oxford University Press.

Leibold, M. A., \& McPeek, M. A. (2006). Coexistence of the niche and neutral perspectives in community ecology. Ecology, 87, 1399-1410.

Leigh, E. G. (2007). Neutral theory: A historical perspective. Journal of Evolutionary Biology, 20, 2075-2091.

Levins, R. (1969). Some Demographic and Genetic Consequences of Environmental Heterogeneity for Biological Control. Bulletin of the Entomological Society of America, 15(3), 237-240.

Loreau, M. (2010). Linking biodiversity and ecosystems: Towards a unifying ecological theory. Philosophical Transactions of the Royal Society B, 365(1537), 49-60.

Lortie, C. J., Brooker, R. W., Choler, P., Kikvidze, Z., Michalet, R., Pugnaire, F. I., \& Callaway, R. M. (2004). Rethinking plant community theory. Oikos, 107, 433-438.

MacArthur, R. H. (1972). Coexistence of species. In J. A. Behnke (Ed.), Challenging biological problems (pp. 253-259). New York: Oxford University Press.

MacArthur, R., \& Levins, R. (1967). The limiting similarity, convergence, and divergence of coexisting species. American Naturalist, 101, 377-385.

MacArthur, R. E., \& Wilson, E. O. (1967). The Theory of island biogeography. Princeton: Princeton University Press.

Margalef, R. (1963). On certain unifying principles in ecology. American Naturalist, 97, 357-374.

Marquet, P., Allen, A., Brown, J., Dunne, J., Enquist, B., Gilloly, J., Gowaty, P. A., Green, J., Harte, J., Hubbell, S. P., O’Dwyer, J., Okie, J., Ostling, A., Ritchie, M., Storch, D., \& West, G. (2014). On theory in ecology. Bioscience, 64, 701-710.

May, R. M. (1974). Stability and complexity in model ecosystems. Princeton: Princeton University Press.

May, R. (1975). Stability in ecosystems: Some comments. In W. H. van Dobben \& R. H. LoweMcConnell (Eds.), Unifying concepts in ecology. Report of the plenary sessions of the first international congress of ecology, The Hague, the Netherlands, 1974 (pp. 161-168). Dordrecht: Springer.

Mccauley, D. J., Young, H. S., Guevara, R., Williams, G. J., Power, E. A., Dunbar, R. B., Bird, D. W., Durham, W. H., \& Micheli, F. (2014). Positive and negative effects of a threatened parrotfish on reef ecosystems. Conservation Biology, 28, 1312-1321. 
McGill, B., Maurer, B. A., \& Weiser, M. D. (2006). Empirical evaluation of neutral theory. Ecology, 87, 1411-1423.

McIntosh, R. P. (1986). The background of ecology. Concept and theory. Cambridge: Cambridge University Press.

McNaughton, S. J. (1977). Diversity and stability of ecological communities: A comment on the role of empiricism in ecology. American Naturalist, 111(979), 515-525.

Mitman, G. (1988). From the population to society: The cooperative metaphors of W.C. Allee and A.E. Emerson. Journal of the History of Biology, 21, 173-192.

Mouquet, N., Devictor, V., Meynard, C. N., Munoz, F., Bersier, L.-F., Chave, J., Couteron, P., Dalecky, A., Fontaine, C., Gravel, D., Hardy, O. J., Jabot, F., Lavergne, S., Leibold, M., Mouillot, D., Münkemüller, T., Pavoine, S., Prinzing, A., Rodrigues, A. S. L., Rohr, R. P., Thébault, E., \& Thuiller, W. (2012). Ecophylogenetics: Advances and perspectives. Biological Reviews, 87, 769-785.

Muneepeerakul, R., Bertuzzo, E., Lynch, H. J., Fagan, W. F., Rinaldo, A., \& Rodriguez-Iturbe, I. (2008). Neutral metacommunity models predict fish diversity patterns in Mississippi-Missouri basin. Nature, 453, 220-222.

Munoz, F., \& Huneman, P. (2016). From the neutral theory to a comprehensive and multiscale theory of ecological equivalence. Quarterly Review of Biology, 91(3), 321-342.

Nicholson, A. J. (1933). 'The Balance of Animal Populations'. Journal of Animal Ecology, 2, $132-178$.

Nicholson, A., \& Bailey, V. (1935). "The Balance of Animal Populations-Part 1". Proceedings of the Zoological Society: 551-598.

Nicoglou, A. (2015). The evolution of phenotypic plasticity: Genealogy of a debate in genetics. Studies in History and Philosophy of Biological and Biomedical Sciences C, 50, 67.

Noss, R. F. (1990). Indicators for monitoring biodiversity: A hierarchical approach. Conservation Biology, 4(4), 355-364.

Odum, E. P. (1953). Fundamentals of ecology. Philadelphia: W. B. Saunders Co.

Orians, G. (1975). Diversity, stability and maturity in natural ecosystems. In W. H. van Dobben \& R. H. Lowe-McConnell (Eds.), Unifying concepts in ecology. Report of the plenary sessions of the first international congress of ecology, The Hague, the Netherlands, 1974 (pp. 139-150). Dordrecht: Springer.

Pimm, S. L. (1984). The complexity and stability of ecosystems. Nature, 307, 321-326.

Pimm, S. L. (1993). The balance of nature? Ecological issues in the conservation of species and communities. Chicago: University of Chicago Press.

Pocheville, A. (2015). The ecological niche: History \& recent controversies. In T. Heams, P. Huneman, G. Lecointre, \& M. Silberstein (Eds.), Handbook of evolutionary thinking in the sciences. Dordrecht: Springer.

Preston, F. W. (1948). The commonness and rarity of species. Ecology, 29, 254-283.

Purves, D. W., \& Turnbull, L. A. (2010). Different but equal: The implausible assumption at the heart of neutral theory. Journal of Animal Ecology, 79, 1215-1225.

Richardson, D. (Ed.). (2011). Fifty years of invasion ecology: The legacy of Charles Elton. London: Wiley.

Rosindell, J., Hubbell, S. P., \& Etienne, R. S. (2011). The unified neutral theory of biodiversity and biogeography at age ten. Trends in Ecology and Evolution, 26, 340-348.

Roughgarden, J. (1979). Theory of population genetics and evolutionary ecology: An introduction. London: Prentice Hall.

Schoener, T. W. (1972). Mathematical ecology and its place among the sciences. Science, 178, 389-391.

Servedio, M. R., Brandvain, Y., Dhole, S., Fitzpatrick, C. L., Goldberg, E. E., et al. (2014). Not just a theory-The utility of mathematical models in evolutionary biology. PLoS Biology, 12(12), e1002017.

Slack, N. (2010). G. Evelyn Hutchinson and the invention of modern ecology. New Haven: Yale University Press.

Smith, F. E. (1952). Experimental methods in population dynamics. Ecology, 33, 441-450. 
Solé, R., \& Goodwin, B. (1988). Signs of life: How complexity pervades biology. New York: Basic Book.

Solé, R. V., Ferrer, R., Montoya, J. M., \& Valverde, S. (2002). Selection, tinkering and emergence in complex networks. Complexity, 8, 20-33.

Solomon, M. E. (1949). The natural control of animal population. Journal of Animal Ecology, 18, 1: $1-1: 34$.

Stearns, S. (1982). The emergence of evolutionary and community ecology as experimental science. Perspectives in Biology and Medicine, 25(4), 621-648.

Strogatz, S. (2001). Exploring complex networks. Nature, 410, 268-276.

Szyrmer, J., \& Ulanowicz, R. E. (1987). Total flows in ecosystems. Ecological Modelling, 35, $123-136$.

Takacs, D. (1996). The Idea of Biodiversity. Philosophies of Paradise. Baltimore and London, John Hopkins University Press.

Tilman, D. (1982). Resource competition and community structure. Princeton: Princeton University Press.

Tilman, D. (1994). Competition and biodiversity in spatially structured habitats. Ecology, 75, 2-16.

Tilman, D. (1996). Biodiversity: Population versus ecosystem stability. Ecology, 77, 350-363.

Ulanowicz, R. E. (1983). Identifying the structure of cycling in ecosystems. Mathematical Biosciences, 65, 219-237.

Ulanowicz, R. E. (1986). Growth and development: Ecosystems phenomenology. New York: Springer.

Vellend, M. (2010). Conceptual synthesis in community ecology. Quarterly Review of Biology, $85,183-206$.

Vellend, M. (2016). The theory of ecological communities. Princeton: Princeton University Press.

Volterra, V. (1926). Variazioni e fluttuarzioni del numero d'individui in specie animali conviventi. Memoria della Reale Accademia Nazionale dei Lincei, 2, 31-113.

Wagner, A. (2005). Robustness and evolvability in living systems. Princeton: Princeton University Press.

Warming, E. (1909). Oecology of plants. Oxford: Clarendon Press.

Watts, D. J., \& Strogatz, S. H. (1998). Collective dynamics in "small-world" networks. Nature, 393, 440.

Williams, G. C. (1966). Adaptation and natural selection. Princeton: Princeton University Press.

Wilson, E. O. (1992). The diversity of life. Cambridge, MA: Belknap Press

Wilson, E. O. (Ed.). (1988). Biodiversity. Washington, DC: National Academy Press.

Open Access This chapter is licensed under the terms of the Creative Commons Attribution 4.0 International License (http://creativecommons.org/licenses/by/4.0/), which permits use, sharing, adaptation, distribution and reproduction in any medium or format, as long as you give appropriate credit to the original author(s) and the source, provide a link to the Creative Commons licence and indicate if changes were made.

The images or other third party material in this chapter are included in the chapter's Creative Commons licence, unless indicated otherwise in a credit line to the material. If material is not included in the chapter's Creative Commons licence and your intended use is not permitted by statutory regulation or exceeds the permitted use, you will need to obtain permission directly from the copyright holder.

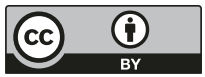

